\title{
Engineering Leadership and Teamwork Development Through Experiential Learning
}

\author{
Kenneth W. Hunter, Sr., Jessica O. Matson \\ Tennessee Technological University
}

\begin{abstract}
The development of teamwork skills has become an established goal of engineering education, and in recent years the development of leadership skills has begun to receive more attention. Experiential learning programs, including activities such as ropes courses and adventure training, have been extensively used in both the corporate and military sectors for teamwork and leadership development. This paper describes a framework that has been used to design experiential learning programs for developing teamwork and leadership skills in undergraduate industrial engineering students. The framework combines elements of traditional experiential learning activities, ropes courses, and the U. S. Army's Leadership Reaction Course in a series of team exercises designed to address specific teamwork and leadership issues. Isomorphic framing is used to present each exercise in a scenario that relates directly to the engineering classroom or workplace, and debriefing sessions are structured to reinforce the transfer of knowledge between the exercise and the classroom or workplace. The framework is flexible and can be easily adapted to a variety of groups, locations, and periods. Examples of different programs and a typical exercise are included. Initial implementations of programs based on this framework have been quite successful, with positive feedback from students, faculty, and industrial advisory board members.
\end{abstract}

\section{Introduction}

Current accreditation standards require engineering programs to demonstrate not only that their graduates have the appropriate mathematical, scientific, and technical knowledge and skills but also that they can function in teams ${ }^{1}$. Results of employer surveys and interviews indicate, however, that the ability to work on a team is an important skill that is lacking in many of today's engineering graduates ${ }^{2,3}$. The development of teamwork skills is thus a critical issue in engineering education.

Likewise, the development of leadership skills is beginning to be seen as another key element in the non-technical side of engineering education. With rapidly increasing technological change, engineers must take stronger leadership roles in industrial and government organizations.

Participants at a recent National Academy of Engineering workshop on the changing nature of engineering practice recommended for the future of engineering education that engineering schools "broaden their curricula" and "make engineering leadership a principal focus." They cited the need for engineers "who can lead real and virtual teams". Landis ${ }^{5}$ has concluded that interaction with peers, interaction with faculty, and involvement in leadership roles with student organizations are among the critical behaviors needed by successful engineering students. 
A survey of 400 of the Fortune 1000 companies in the U.S. also provides impetus to increase the leadership skills of engineering graduates. The survey yielded the following conclusions ${ }^{6}$.

1. Leadership skills are needed in today's workforce.

2. The need for leadership skills is accelerating due to global competition, information technology, the need for agile organizations, the need for working in teams, and demographic changes in the workforce.

3. Companies in the survey are "short on leaders."

4. Few of the companies provide leadership training except to upper-level management.

5. Leadership effectiveness is evaluated most often by measures of team performance.

Thus, providing for the development of both teamwork and leadership skills in the engineering curriculum will better prepare graduates for success in the real world.

Today's accreditation criteria also specify that the inputs of constituents must be considered in the process of continuous improvement of the engineering curriculum. For several years, members of the Industrial Advisory Board for the industrial engineering program at Tennessee Technological University have strongly recommended the implementation of leadership development education within the industrial engineering curriculum. After study in response to their recommendations, a new one-credit elective course, IME 490 Engineering Leadership, was developed. Feedback from this course, from graduating senior exit interviews, and from assessment of junior- and senior-level courses requiring team-based projects pointed to the need for additional and earlier introduction of teamwork and leadership skill-building in the curriculum. This paper describes a framework that has been used to design experiential learning programs for developing teamwork and leadership skills in undergraduate industrial engineering students at Tennessee Tech. The framework is especially well suited for designing programs to provide just-in-time education in these areas.

\section{Framework for Program Design}

The framework for program design is based on the selection, adaptation, and facilitation of experiential learning activities that address the specific teamwork and/or leadership needs of a course or group. It employs proven practices selected to meet the needs of and appeal to engineering students. The framework consists of four steps:

1. Defining the program goals.

2. Selecting the program exercises.

3. Framing the exercises.

4. Debriefing participants with emphasis on application.

The following sections describe and explain the purpose of each step.

\subsection{Defining the Program Goals}

In order to achieve the best results in the available time and to maintain the focus of the participants, each program should be designed to address a limited set of teamwork and/or 
leadership issues. Defining the specific issues to be addressed can be a difficult task as there is a tendency to keep broadening the program scope, and the inclusion of too many topics may weaken the effectiveness. A half-day program can typically cover three or four major topics.

For example, the overall goal of a program might be to introduce the basic concepts of teamwork, to improve leadership skills, or to improve one or more specific teamwork skills needed in a particular course. Numerous examples of teamwork and leadership issues exist in the literature. For example, $\mathrm{Smith}^{7}$ focuses on five issues: communication, leadership, decisionmaking, conflict management, and team organization/norms. Similarly, McGourty and De Meuse $^{8}$ focus on communication, decision-making, collaboration, and self-management, but they further define communication by the key roles of active listener and influencer. A program might be focused on the broad topic of communication or more narrowly on active listening.

\subsection{Selecting the Program Exercises}

The framework for program design utilizes experiential learning. The research foundation for experiential learning was provided by Dewey ${ }^{9}$ in 1938 and refined more recently by Kolb ${ }^{10}$. Kolb proposed a model for effective experiential learning consisting of concrete experience, reflective observation, abstract conceptualization, and active experimentation. In its simplest form, experiential learning consists of active participation in an experience, purposeful reflection on the experience to understand its implications, and application of the knowledge gained to other areas.

Lewis, Aldridge, and Swamidass ${ }^{11}$ noted that "there is an emerging consensus about how one can promote effective teaming skills." First, there must be a focus on teaming. A second requirement is that practice and reflection must be promoted. Third, the quality of team processes must be monitored for intervention. Citing Kolb ${ }^{10}$, they also pointed out that teamwork skills are "best learned experientially by actively participating as a member of successful work teams." Numerous other studies on team building, e.g., Bronson et al. ${ }^{12}$, have demonstrated the effectiveness of experiential learning and adventure training involving physical activities.

Kaagan ${ }^{13}$ reviewed the work of several noted researchers who have similarly concluded that experiential methods are the most effective for leadership development. The key elements for effective leadership development are experience and well-facilitated discussions in a "doing and reflecting sequence"; the outcome is learning that is "deeper, more consequential, and more enduring." For many years, leadership reaction courses involving experiential learning have been a major component of basic leadership training in the U.S. Army Infantry School, U.S. Army Engineer School, U.S. Marine Corps, and other military organizations.

There are many proven exercises available for use in experiential learning programs. Available exercises include the following types:

1. Socialization activities for familiarizing people in the group.

2. Group initiatives, or group problem-solving tasks, for focusing on specific skills.

3. Ropes or challenge course events for focusing on specific skills with added elements of physical and psychological challenge. 
There are numerous collections of experiential learning exercises that provide detailed guidelines for implementation, such as Kaagan ${ }^{13}$ and Rohnke ${ }^{14}$. Exercises should be selected to address the specific issues and program goals defined in step 1 and should be sequenced for maximum effect. For example, socialization activities, if needed, would generally be scheduled before group initiatives, and the initial group initiatives should ensure success to build group confidence. Other guidelines on sequencing can be found in Kaagen ${ }^{13}$. Additional selection criteria might include the number of participants, the need to accommodate students with disabilities, training/safety considerations, and available facilities.

Research ${ }^{15,16}$ has shown that multiple, shorter, more focused activities involving experiential learning result in greater understanding and more change than single-event multi-day or multiweek programs. The framework accommodates programs of any length. A two-hour laboratory period might be sufficient for a program focused only on improving students' active listening skills, whereas a full day might be needed for a program designed to improve basic leadership skills. While the framework is not restricted to just-in-time application, it lends itself to a series of programs with such an objective.

The location of the program may influence the exercises selected but should have little effect on program outcomes if the appropriate exercises are selected. Well-designed programs have been shown to produce equivalent results regardless of location (indoor or outdoor) ${ }^{17}$ or setting (hotel or camp $)^{16}$. Expensive facilities such as a ropes course are not required. Many of the exercises can be implemented with readily available materials at little expense.

\subsection{Framing the Exercises}

The framing of an exercise is the context in which it is presented to the participants. The most typical forms of framing include fantasy, reality and isomorphic. Isomorphic framing presents the exercise in a context familiar to the participants, such as the engineering workplace or classroom. The use of isomorphic framing has been found to supplement the debriefing process and enhance the transfer of knowledge from the exercise to the workplace ${ }^{18}$. Including fictional or fantasy elements in an otherwise isomorphic framing scenario can make the exercise more fun for the participants and still provide the desired results.

For example, the Telephone Pole Shuffle ${ }^{14}$ is an exercise that requires two groups to pass each other while traversing a pole lying on the ground. The groups are moving in opposite directions and cannot step off the pole. Reality framing would present the exercise as two groups traversing a pole on the ground. Fantasy framing might describe the pole as a bridge over the cone of a volcano on the planet Mercury and the participants as astronauts rushing to get to their spacecraft before the volcano erupts. Isomorphic framing might present the exercise to a group of industrial engineering students in the context of a problem in material handling, workflow, or logistics.

\subsection{Debriefing Participants with Emphasis on Application}

The most critical part of implementing an experiential learning exercise is the debriefing of the participants. One of the most effective techniques is metaphoric debriefing, which attempts to 
draw clear parallels between the exercise and the workplace or classroom ${ }^{18}$. Kaagan $^{13}$ recommends a series of questions that address, in order:

1. What happened during the exercise?

2. What can be implied from the experience?

3. How can the knowledge gained be applied in the workplace?

Careful preparation of questions in each of these areas and good facilitation are essential to achieving optimum results from the program. Participants should do most of the talking during the debriefing and all participants should be encouraged to contribute. The facilitator must ensure that the specific issues and program goals related to the exercise have been fully addressed, especially the application of the exercise results to the workplace. Rehearsal of exercises and debriefing sessions by facilitators is strongly recommended.

\section{Program Example}

One of the implementations of the framework at Tennessee Tech has been a workshop designed to improve teamwork skills in the capstone design course for industrial engineering students. IME 451 Engineering Design Internship is a required senior course that places student teams into real, unstructured design projects with industrial partners. The course was designed with a focus on teamwork, and methods for promoting teamwork had already been incorporated in the course. For example, at the beginning of the course in a traditional lecture format, the instructors reviewed teamwork roles and guidelines for effective teamwork. During the course, the student teams were required to develop a schedule for project management, to maintain a project log, and to make weekly progress reports. The instructors reviewed the project logs and met regularly with the teams. The course grade was based partially on team effectiveness. However, the instructors' assessment of student performance in the course pointed to weaknesses in the students' teamwork skills. In particular, the following skills were frequently weak:

1. Communication with external agents/industry and instructors (seeking information and reporting status) and within the group (active listening).

2. Planning with limited initial information, ambiguity, and time constraints, and incorporating flexibility.

3. Project management including time management, rehearsal, and flexibility.

4. Team organization and leadership, in particular team leadership, utilization of personnel, fostering collaboration, and conflict resolution.

5. Risk-taking to improve innovation, inquiry, and creativity.

To improve students' skills in these areas, a four-hour workshop was designed to accommodate four five-member project teams. Since these teams would work together for the entire semester, the workshop also served as a team-building experience. The workshop consisted of a personal assessment questionnaire and the six team exercises listed below.

1. Working Norms ${ }^{13}$, an exercise focused on team organizational structure, communication within the team, and expectations for individual team member performance. 
2. Logistic Linkages (based on Magic Steps ${ }^{13}$ ), an exercise focused on planning and innovation.

3. The Ergo Monster (based on The Monster ${ }^{14}$ ), an exercise focused on planning, innovation, and resource utilization. This exercise also builds trust through physical activity and contact.

4. Shaping the Future ${ }^{13}$, an exercise focused on communication, planning, and decisionmaking.

5. Senior Design Maze (based on Innovation Maze ${ }^{13}$ ), an exercise focused on leadership, followership, and risk-taking.

6. Big Business ${ }^{14}$, an exercise focused on project management, time management, and resource utilization.

Since the participants already knew each other, no socialization activities were required. The workshop began with a brief overview of the goals and agenda and a personal assessment questionnaire designed to stimulate thinking about teamwork and leadership issues. The Working Norms exercise was assigned as the first team activity, but no time was allotted for it. For this exercise, teams were instructed to develop a set of team operating rules as time was available and to present their list at the close of the workshop. This assignment not only focused team members on their expectations of each other and the team but also added the element of time management. Teams rotated through the next four exercises in thirty-minute intervals. The final exercise was conducted with all teams simultaneously and provided an element of competition.

As an example of an exercise and how it can be applied to address specific skills or issues, consider "Senior Design Maze." In the workshop described above, this exercise was used to address leadership, followership, and risk-taking. The debriefing focused on these issues in the context of the senior design project. A facilitator's guide complete with isomorphic framing and a sequence of debriefing questions is included in the Appendix.

\section{Implementation Experience and Conclusions}

As previously stated, the framework is flexible and can be easily adapted to a variety of groups, locations, and periods. In addition to the program for IME 451 discussed above, the framework has been used to design two other programs for industrial engineering students at Tennessee Tech, each with a slightly different goal. For IME 200, Introduction to Industrial Engineering, the program was designed to provide sophomore and transfer students with an introduction to both leadership and teamwork skills. It was conducted at a nearby 4-H camp and utilized low ropes activities. The underlying goals for this program were to better prepare students for teamwork in course projects and leadership in student organizations and to build esprit de corps in the department. For IME 490, Engineering Leadership, the program was designed to provide students with opportunities to develop and practice leadership skills. It was conducted on campus and utilized leadership reaction course activities and a rappelling tower. The underlying goals for this program were to better prepare students for engineering careers and/or graduate study.

Proceedings of the 2001 American Society for Engineering Education Annual Conference \& Exposition Copyright (C) 2001, American Society for Engineering Education 
Although the evidence is preliminary and primarily qualitative, these initial implementations appear to have been quite successful, with positive feedback from student participants, faculty, and industrial advisory board members. Limited quantitative data from participant surveys indicate a need for further study of gender differences, effectiveness of specific exercises, and other program variables. Investigation of appropriate assessment methods is ongoing.

Appendix - Example Exercise: Senior Design Maze (based on Innovation Maze ${ }^{13}$ )

Issues Addressed: Leadership, followership, and risk-taking

Required Materials: 5 x 7 grid of 18" squares (masking tape, engineer tape) Solution diagram

Pre-exercise Facilitation: None

Instructions to Team:

This is a group problem-solving exercise about leadership and followership, the mutual support required for teamwork, and risk-taking. This grid or maze represents a consulting project somewhat like your senior design project. Each cell represents a potential step toward completion of the project. There is an underlying path that will ultimately result in successful completion of the project. To complete the project, you must get all group members through the maze by following that single path. The path is formed by adjacent squares, to either side, forward, backward, or diagonally, and is known only to me. Your team will be awarded $\$ 1$ million if you complete the project (get through the maze) in the time allotted. However, you will be assessed a $\$ 100,000$ penalty for each rule violation. Here are the rules.

1. Only one person at a time is allowed on the maze.

2. If a person steps on a wrong square, he or she will be buzzed and must withdraw from the maze. There is no penalty for being buzzed. To withdraw successfully, however, a person must follow the exact same path used to get in. If he or she fails to do so, a penalty will be assessed.

3. When a person is buzzed off, another team member must make the next attempt. The team must establish a batting order and stick to it.

4. There should be no "Hansel and Gretel," that is, leaving a trail of crumbs on the maze for others to follow. Likewise, no maps can be used or created.

5. When in the planning mode, the entire group must be behind the start line, and talking is allowed. When a team member is on the maze, talking is not allowed, but team members may array themselves around the maze in any way they choose. A penalty will be assessed for talking while someone is on the maze.

6. When a team member is on the maze, other team members may not touch the maze. A penalty will be assessed for violating this rule.

7. The time limit is 15 minutes. 
Post-exercise Facilitation:

What Happened Questions

1. How much money did your team win?

2. Did anyone assume a leadership role? What was the organizational structure during the exercise? Who were the leaders and the followers?

3. Describe your group strategy for getting through the maze. What worked and what didn't? What was your strategy to support the person who was out on the maze?

4. What emphasis did your group give to planning as opposed to execution?

5. What was the penalty for stepping on a wrong square? If there was no explicit penalty, why did you hesitate in choosing the next square?

Implication Questions

1. What leadership and organizational structure would work best for this exercise?

2. What was the essential task or tasks involved in this exercise? Beyond the obvious one of getting all members through the maze, what was the exercise all about?

3. What are the lessons for how leaders should behave in organizations? (support for making mistakes, learning from mistakes, having support systems for innovators, letting group intelligence prevail)

4. How do we learn from the mistakes of those who have gone before us?

Application Questions:

1. Relate the path in the Senior Design Maze to your IME 451 project. (exact path unknown, not a straight line, backtracking, next step and number of steps uncertain, must risk making a mistake to make progress, entire team is important for success)

2. What type of leadership and organizational structure would work best for your team?

3. How does prior experience (e.g., co-op) affect success with a new project (maze)?

4. How does this relate to the need for innovation in your senior design project?

\section{Solution Diagram}

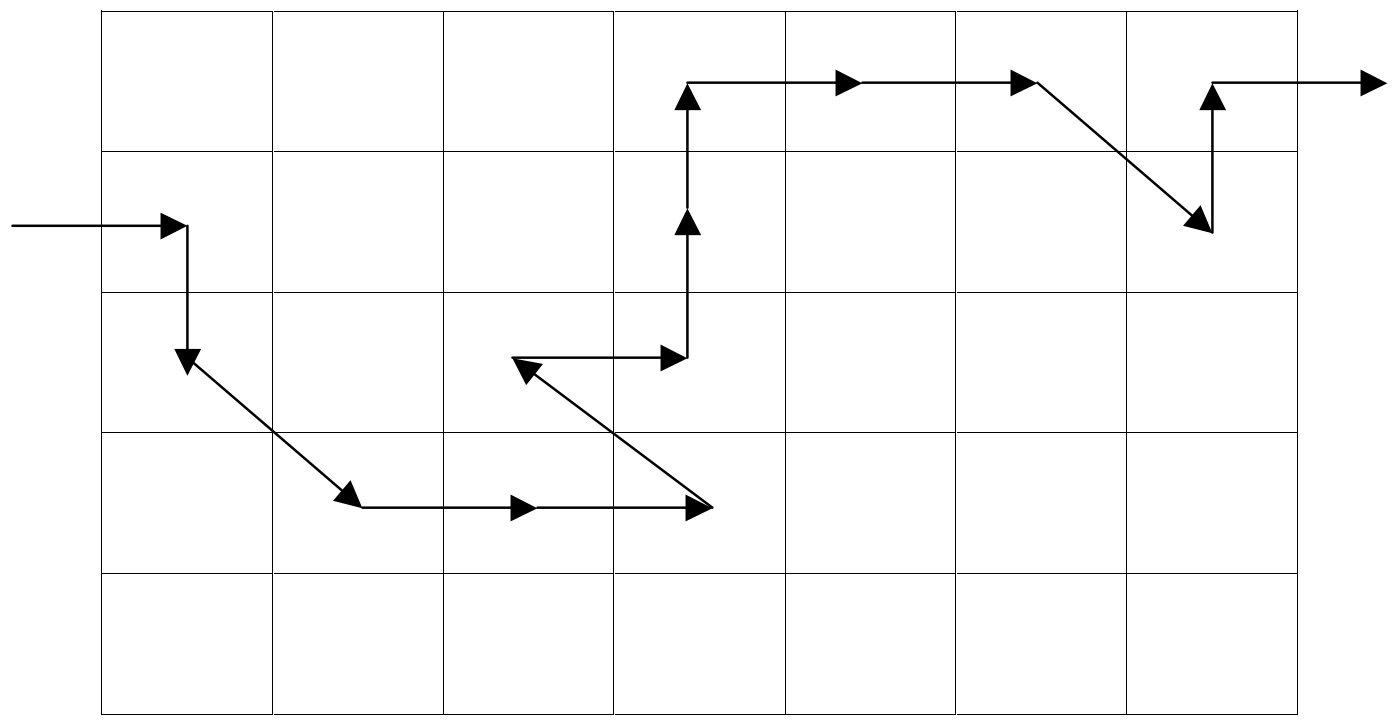

Proceedings of the 2001 American Society for Engineering Education Annual Conference \& Exposition Copyright (C) 2001, American Society for Engineering Education 
Bibliography

1. Accreditation Board for Engineering and Technology, Engineering Criteria 2000.

2. Katz, Susan M. The Entry-Level Engineer: Problems in Transition from Student to Professional. Journal of Engineering Education. 82(3), July 1993, 171-174.

3. Real-World 101. ASEE Prism. October 1992, 19-22.

4. Morgan, R. P., P. P. Reed, and W. A. Wulf. The Changing Nature of Engineering. ASEE Prism. May-June 1998.

5. Landis, R. B. Enhancing Engineering Student Success: A Pedagogy for Changing Behaviors. Proceedings of the 1997 ASEE Annual Conference. Milwaukee, June 1997.

6. Csoka, Louis S. Bridging the Leadership Gap. Report Number 1190-98-RR, The Conference Board, New York, 1998.

7. Smith, Karl A. Project Management and Teamwork. McGraw-Hill, 2000.

8. McGourty, Jack, and Kenneth P. De Meuse. The Team Developer. Wiley Custom Services, 2000.

9. Dewey, J. Education and Experience. Collier, 1938.

10. Kolb, D. A. Experiential Learning: Experience as the Source of Learning and Development. Prentice-Hall, 1984.

11. Lewis, Philip, Dayne Aldridge, and Paul M. Swamidass. Assessing Teaming Skills Acquisition on Undergraduate Project Teams. Journal of Engineering Education. April 1998, 149-155.

12. Bronson, J., S. Gibson, R. Kishar, and S. Priest. Evaluation of Team Development in a Corporate Adventure Training Program. Journal of Experiential Education. 15(2), 50-53.

13. Kaagan, Stephen S. Leadership Games. Sage Publications, 1999.

14. Rohnke, Karl. Silver Bullets. Project Adventure, 1984.

15. Zenger, J., D. Ulrich, and N. Smallwood. How Leaders Develop Leaders. Training and Development. 54(3), March 2000.

16. Priest, S. The Effect of Program Setting and Duration on Corporate Teamwork Development. Study No. 23, http://members.tscnet.com/pages/experien.

17. Priest, S. The Effect of Program Location and Design on Corporate Teamwork Development. Study No. 24, http://members.tscnet.com/pages/experien.

18. Priest, S. A Comparison of Metaphoric Debriefing and Isomorphic Framing in CAT Programs. Study No. 11, http://members.tscnet.com/pages/experien.

\section{KENNETH W. HUNTER, SR.}

Kenneth Hunter is currently Director of the Basic Engineering Program at Tennessee Technological University. He received his B.S. and M.S. degrees in mechanical engineering from Tennessee Tech. He has 25 years of engineering experience, including positions in academia, industry, the military, a government laboratory, and his own consulting business. He is a registered P.E. in the State of Tennessee.

\section{JESSICA O. MATSON}

Jessica Matson is currently Professor and Chairperson of the Industrial and Manufacturing Engineering Department at Tennessee Technological University. She received her B.S. from Mississippi State University and her M.S. and $\mathrm{Ph} . \mathrm{D}$. from the Georgia Institute of Technology, all in industrial engineering. She has previously served on the faculty at Mississippi State University and the University of Alabama and is a registered P.E. (Mississippi). 